\title{
Article \\ The Improvement of Energy Storage Performance by Sucrose-Derived Carbon Foams via Incorporating Nitrogen Atoms
}

\author{
Malgorzata Skorupska ${ }^{1}$, Piotr Kamedulski ${ }^{1}$ D, Jerzy P. Lukaszewicz ${ }^{1,2}$ and Anna Ilnicka ${ }^{1, *(D)}$ \\ 1 Faculty of Chemistry, Nicolaus Copernicus University in Torun, Gagarina 7, 87-100 Torun, Poland; \\ m.skorupska@doktorant.umk.pl (M.S.); pkamedulski@umk.pl (P.K.); jerzy_lukaszewicz@o2.pl (J.P.L.) \\ 2 Centre for Modern Interdisciplinary Technologies, Nicolaus Copernicus University in Torun, Wilenska 4, \\ 87-100 Torun, Poland \\ * Correspondence: ailnicka@umk.pl; Tel.: +48-609-273-793
}

check for updates

Citation: Skorupska, M.; Kamedulski, P.; Lukaszewicz, J.P.; Ilnicka, A. The Improvement of Energy Storage Performance by Sucrose-Derived Carbon Foams via Incorporating Nitrogen Atoms. Nanomaterials 2021, 11, 760. https:// doi.org/10.3390/nano11030760

Academic Editor: Marcin Wysokowski

Received: 21 February 2021

Accepted: 13 March 2021

Published: 17 March 2021

Publisher's Note: MDPI stays neutral with regard to jurisdictional claims in published maps and institutional affiliations.

Copyright: (c) 2021 by the authors. Licensee MDPI, Basel, Switzerland. This article is an open access article distributed under the terms and conditions of the Creative Commons Attribution (CC BY) license (https:/ / creativecommons.org/licenses/by/ $4.0 /)$.

\begin{abstract}
This paper addresses the problem of improving electrochemical energy storage with electrode materials obtained from common raw ingredients in a facile synthesis. In this study, we present a simple, one-pot route of synthesizing microporous carbon via a very fast reaction of sucrose and graphene (carbon source), chitosan (carbon and nitrogen source), and $\mathrm{H}_{3} \mathrm{PO}_{4}$. Porous carbons were successfully produced during high temperature carbonization, using nitrogen as a shielding gas. Samples were characterized using X-ray powder diffractometry, elemental analysis, $\mathrm{N}_{2}$ adsorption-desorption measurements, scanning electron microscopy, and Raman spectroscopy. The developed carbon material possessed a high surface area, up to $1313 \mathrm{~m}^{2} \mathrm{~g}^{-1}$, with no chemical or physical activators used in the process. The structural parameters of the microporous carbons varied depending on the ratio of reagents and mass composition. Samples were prepared both with and without chitosan. The present synthesis route has the advantages of being a single-step approach and only involving low-cost and environmentally friendly sources of carbon. More importantly, microporous carbon was prepared without any activators and potentially offers great application in supercapacitors. Cyclic voltammetry and constant current charge-discharge tests show that sucrosebased porous carbons show excellent electrochemical performance with a specific capacitance of up to $143 \mathrm{~F} \mathrm{~g}^{-1}$ at a current density of $1 \mathrm{~A} \mathrm{~g}^{-1}$ in a $6 \mathrm{M} \mathrm{KOH}$ electrolyte.
\end{abstract}

Keywords: graphene; sucrose; chitosan; carbonization; carbon nanocomposite; microporous structure; surface functional groups

\section{Introduction}

Fabrication of electrochemical energy storage devices (batteries and supercapacitors) greatly relies on carbon-based electrodes. Therefore, improving the efficiency of these devices will rely on new findings in the area of carbon electrode material synthesis. Solutions encompassing a wide accessibility of raw materials, acceptable market price, and facile processing are in high demand due to the need of eventual mass production. Natural materials such as biomass and carbohydrates (e.g., glucose, fructose, lactose, and cellulose), which have natural reserves, are being extensively studied as a source of carbon-based materials. Due to its uniform structure, very low price, local availability, and high chemical purity, sucrose is one of the most attractive carbon precursors. There are essentially two main approaches that can be applied to extracting carbon from sucrose, either a hydrothermal [1] or a heat-treatment process [2-5]. To improve the porous structure of sucrose-based carbon, a variety of activation methods have been developed, which use steam [6], $\mathrm{CaCO}_{3}$ [7], $\mathrm{NaHCO}_{3}$ [8], polyurethane as a template [9], $\mathrm{CO}_{2}$ gas [10], $\mathrm{LiOH}$ [11], $\mathrm{NaOH}$ [11-13], $\mathrm{KOH}[11,14,15], \mathrm{H}_{3} \mathrm{PO}_{4}, \mathrm{ZnCl}_{2}, \mathrm{SnCl}_{2}$, or $\mathrm{CaCl}_{2}$ [16]. Another approach to synthesis is to activate sucrose mechanically [17-19]. The micropore volume in a sucrose-based structure 
may depend on dehydrating acids (sulphuric, hydrochloric, phosphoric, oxalic, acetic, citric, and tartaric acid) and the cationic component $\left(\mathrm{Ca}\left(\mathrm{NO}_{3}\right)_{2},(\mathrm{NH} 4)_{2} \mathrm{SO}_{4},\left(\mathrm{NH}_{4}\right)_{2} \mathrm{CO}_{3}, \mathrm{NH}_{4}\right)$ used during synthesis [20]. Using the carbonization of a triblock copolymer (P123), silica, and sucrose composite, highly ordered mesoporous carbon has been generated [21,22].

Electrode materials based on activated carbon are widely used in supercapacitors [23,24] and Li-ion batteries $[25,26]$. In our previous research, we found that pyrrolic-N $(\mathrm{N}-5)$, pyridinic- $\mathrm{N}(\mathrm{N}-6)$, and quaternary-N $(\mathrm{N}-\mathrm{Q})$ groups, active in catalytic reactions, are present in carbon obtained using chitin, chitosan, green algae, or amino acids as a source [27-29]. Therefore, using one of these precursors during the synthesis of sucrose-based carbon for supercapacitors should augment energy storage performance. Recently, the electrochemical properties of sucrose-derived carbon were improved by doping with $\mathrm{N}, \mathrm{F}$, and B, utilizing $\mathrm{H}_{3} \mathrm{BO}_{3}$ or $\mathrm{NH}_{4} \mathrm{~F}$ as heteroatom precursors [9]. Huang et al. prepared chemically activated carbon (with $\mathrm{KOH}$ ) for electric double layer capacitors (EDLC) with a very modest specific capacitance of only $\sim 40 \mathrm{~F} \mathrm{~g}^{-1}$ [30]. For porous carbon materials prepared by Guo et al. via high-temperature pyrolysis, the capacitance equaled $232 \mathrm{~F} \mathrm{~g}^{-1}$ at a current density of $0.1 \mathrm{~A} \mathrm{~g}^{-1}$ [31]. In another study, Subramanian et al. used sucrose pre-treated with ammonia nitrate as the carbon source to prepare a porous carbon with a specific capacitance of $232 \mathrm{~F} \mathrm{~g}^{-1}$ [32]. Silicon nanowires coated with sucrose-derived carbon were prepared for supercapacitor application [33] as well. The disadvantages of the mainstream electrode material production methods are the often multiple-step procedures, environmentally unfriendly reagents, and the presence of metals or metal oxides in the materials' structure.

Recognizing the applicability of sucrose in $\mathrm{N}$-doped carbon electrode materials was the main motivation of the current study. To the best of the authors' knowledge, so far, there have been no reports of a one-pot synthesis of porous carbon foam from materials such as hydrocarbons and graphene, without using an activation agent. In this paper, different carbon and nitrogen contents were prepared in a carbonization process using sucrose and graphene as carbon sources and chitosan as a carbon and nitrogen source; their structural and electrochemical properties were evaluated. By changing the ratio of reagents, well-developed micro or mesoporous structures were obtained. The use of chitosan caused nitrogen groups to be introduced into the porous foam carbon structure.

\section{Materials and Methods}

\subsection{Materials}

Graphene nanoplatelets $\left(750 \mathrm{~m}^{2} \mathrm{~g}^{-1}\right)$ and chitosan were purchased from Sigma Aldrich (branch in Poland). Sucrose was purchased from Krajowa Spolka Cukrowa S.A. (Torun, Poland). Other reagents, i.e., $\mathrm{H}_{3} \mathrm{PO}_{4}$ and $\mathrm{CH}_{3} \mathrm{COOH}$, were purchased from $\mathrm{POCH}$ (Gliwice, Poland).

\subsection{Preparation of Carbon Foams}

Carbon foams were synthesized in one of two ways. In the first path, to 3 or $5 \mathrm{~g}$ of sucrose, 1 or $3 \mathrm{~g}$ of graphene nanoplatelets was added and mixed well. In the second, to 3 or $5 \mathrm{~g}$ of sucrose, 1 or $3 \mathrm{~g}$ of chitosan was added, previously dissolved in $10 \mathrm{~mL}$ of a $1 \% \mathrm{CH}_{3} \mathrm{COOH}$ solution, then mixed. In the next step, the mixtures were treated with 3 or $4.5 \mathrm{~mL}$ of $\mathrm{H}_{3} \mathrm{PO}_{4}$ at a 3:1 and 5:3 ratio of reagents, respectively. Samples were then heated on a double electric cooker at temperatures in the range of 100 to $400{ }^{\circ} \mathrm{C}$. After this, materials were carbonized in a $\mathrm{N}_{2}$ atmosphere at a heating rate of $10^{\circ} \mathrm{C} \mathrm{min}-1$ until $900{ }^{\circ} \mathrm{C}$ was reached. This temperature was maintained for $1 \mathrm{~h}$. The process was carried out in a tubular furnace (Thermolyne F21100) (NIST, Gaithersburg, MD, USA). Further in the text, the mixture of sucrose (S) and chitosan (CS) used during synthesis is denoted as SCS. The mixture of sucrose (S) and graphene nanoplatelets (GF) is denoted as SGF. The mass ratio (R) of reagents used, S:CS and S:GF, was either 3:1 or 5:3. The samples in general are indicated as SCS-R (SCS-3:1, SCS-5:3) and SGF-R (SGF-3:1, SGF-5:3). 


\subsection{Structure Characterization}

The morphology of the obtained samples was determined using a scanning electron microscope (SEM 1430 VP, LEO Electron Microscopy Ltd., Oberkochen, Germany) operating at $30 \mathrm{kV}$. The porous structure of the samples was analyzed via a nitrogen adsorption experiment at $77 \mathrm{~K}$, using an automatic adsorption instrument, ASAP 2020 Plus (Micromeritics, Norcross, GA, USA). Before the analysis, obtained carbons were outgassed in a vacuum at $200{ }^{\circ} \mathrm{C}$ for $24 \mathrm{~h}$. The samples' surface areas were calculated using the Brunauer-Emmett-Teller (BET) equation, and the pore size distributions were calculated using the nonlocalized density functional theory (NLDFT) method. The elemental composition of the materials was analyzed by means of a combustion elemental analyzer (Vario CHN, Elementar Analysensysteme GmbH, Langenselbold, Germany). Raman spectra were obtained by a Renishaw InVia Raman analyzer (laser wavelength $532 \mathrm{~nm}$, Renishaw Company, Gloucestershire, UK). X-ray photoelectron spectroscopy (XPS, PHI5000 VersaProbe II Scanning XPS Microprobe, Chigasaki, Japan) measurements were performed using a monochromatic $\mathrm{Al} \mathrm{K} \alpha \mathrm{X}$-ray source. Survey spectra were recorded for all samples in the energy range of 0 to $1300 \mathrm{eV}$ with a $0.5 \mathrm{eV}$ step, while high-resolution spectra were recorded with a $0.1 \mathrm{eV}$ step.

\subsection{Electrochemical Measurements}

The electrochemical performance of carbon samples was studied using cyclic voltammetry $(\mathrm{CV})$ curves, galvanostatic charge-discharge (GCD) cycling, and electrochemical impedance spectroscopy (EIS) plots for a two-electrode system. Electrodes prepared for electrochemical measurements were well-mixed active materials, conductive carbon black (C-140), and polytetrafluoroethylene (PTFE) at a mass ratio of 17:2:1. These, at a diameter of $9.25 \mathrm{~mm}$, were dried in a vacuum oven at $100^{\circ} \mathrm{C}$ for $24 \mathrm{~h}$. Electrochemical capacitors were built using two carbon electrodes with comparable mass $(4-5 \mathrm{mg})$. Cyclic voltammetry and galvanostatic charge-discharge data were collected using a potentiostat-galvanostat (PGSTAT128N, Autolab) (Metrohm Autolab B.V., Utrecht, The Netherlands). Electrochemical investigations were performed in $6 \mathrm{M} \mathrm{KOH}$ aqueous electrolyte. Cyclic voltammograms were recorded at a scan rate between 5 and $200 \mathrm{mV} \mathrm{s}^{-1}$, in the potential range of 0 to $0.9 \mathrm{~V}$. Charging-discharging was performed at various current densities, from 0.1 to $40 \mathrm{~mA} \mathrm{~g}^{-1}$. Electrochemical impedance was measured in a frequency range of $10^{-1}$ to $10^{5} \mathrm{~Hz}$; the amplitude was $10 \mathrm{mV}$. Two electrodes of similar mass were used in a symmetrical twoelectrode supercapacitor. The specific capacitance $\mathrm{C}_{\mathrm{s}}\left(\mathrm{F} \mathrm{g}^{-1}\right)$ (Equation (1)), energy density $\mathrm{E}\left(\mathrm{Wh} \mathrm{kg}^{-1}\right)$ (Equation (2)), and power density $\mathrm{P}\left(\mathrm{W} \mathrm{kg}^{-1}\right)$ (Equation (3)) were calculated based on the following equations:

$$
\begin{gathered}
\mathrm{C}_{\mathrm{s}}=\mathrm{I} \times \Delta \mathrm{t} /(\mathrm{m} \times \Delta \mathrm{V}) \\
\mathrm{E}=\left(\mathrm{C} \times \Delta \mathrm{V}^{2}\right) /(8 \times 3.6) \\
\mathrm{P}=(\mathrm{E} \times 3600) / \Delta \mathrm{t}
\end{gathered}
$$

where I is the charge and discharge current $(\mathrm{A}), \Delta \mathrm{t}$ is the discharge time (s), $\Delta \mathrm{V}$ is the potential change within the discharge time $(\mathrm{V})$, and $\mathrm{m}$ is the total mass of active materials in both electrodes.

\section{Results and Discussion}

\subsection{Characterization of Carbon Materials}

New carbon-based materials have been synthesized and characterized according to the specific underlying motivation: recognizing the applicability of sucrose for $\mathrm{N}$-doped carbon electrode materials. Particular attention was paid to the insertion of nitrogen atoms, commonly regarded as the way to improve electric charge storage. Moreover, the authors searched for the most facile synthesis route. Characterization included key features like 
surface area and pore structure, microscopic structure and morphology, bulk and surface elemental composition, as well as collection of a complete set of electrochemical profiles.

Figure 1 shows scanning electron micrographs for samples obtained from sucrose with two different modifications-chitosan and graphene. The pores developed under chitosan influence are interdigitated with each other to form a three-dimensional (3D), interconnected frame structure, the morphology of the carbon materials being sensitive to chitosan use. This special structure enables the pores inside the material to communicate with each other and allows the electrolyte to penetrate the electrode material more smoothly, accelerate the transport of electrolyte ions, reduce the "traffic blockage" in the ion transport process, and thus improve capacitance performance [34,35]. The SCS-R samples (Figure 1a,c) and SGF-R samples (Figure 1b,d) exhibit differences in morphology. A smooth surface of carbon can be attributed to a lower specific surface area $\left(\mathrm{S}_{\mathrm{BET}}\right)$ when comparing SGF-3:1 and SGF-5:3 to SCS-3:1 and SCS-5:3 carbon, respectively, as described in Table 1.

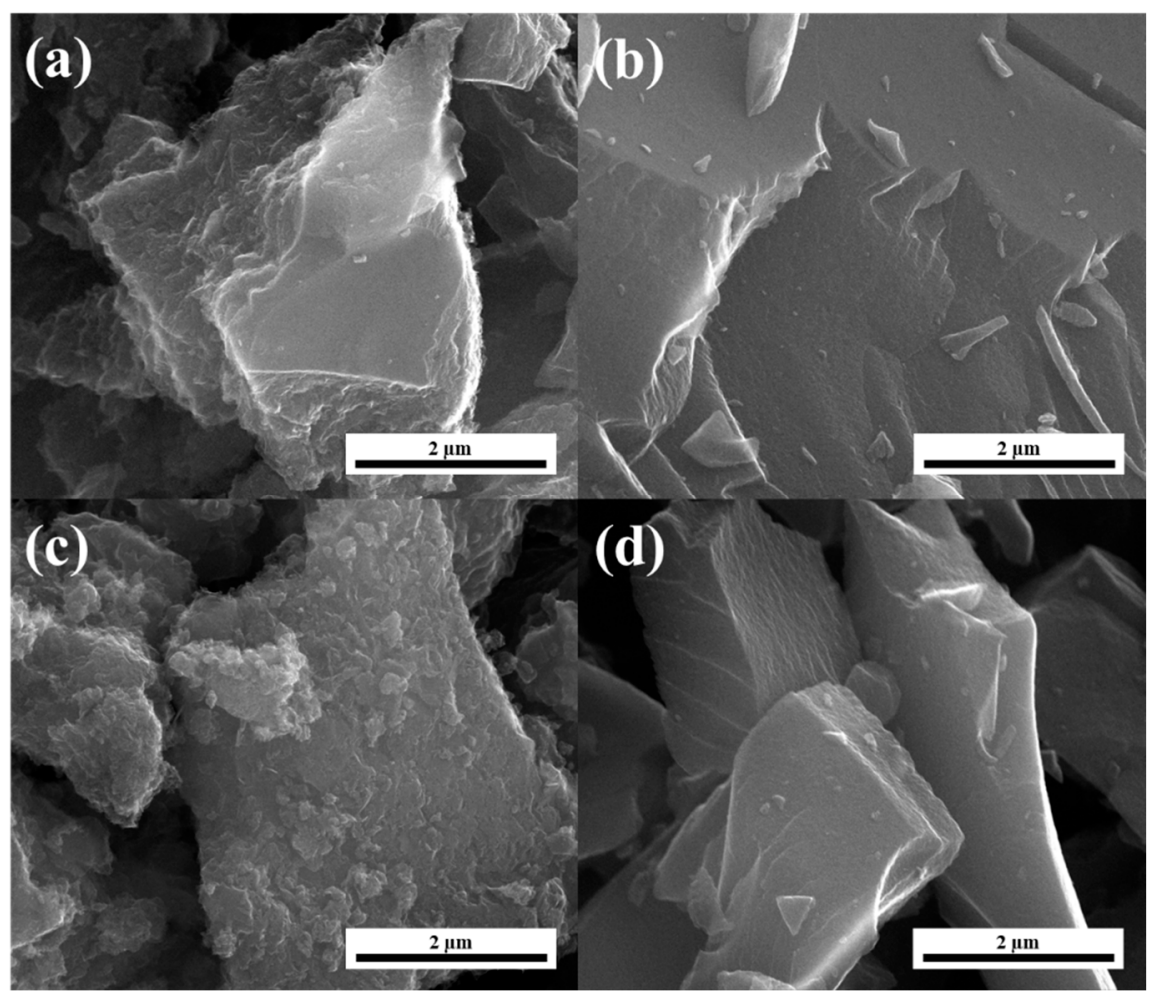

Figure 1. SEM images of the (a) mixture of sucrose and graphene nanoplatelets with a 3:1 ratio (SGF-3:1), (b) mixture of sucrose and chitosan with a 3:1 ratio (SCS-3:1), (c) mixture of sucrose and graphene nanoplatelets with a 5:3 ratio (SGF-5:3), and (d) mixture of sucrose and chitosan with a 5:3 ratio (SCS-5:3) sample.

Table 1. Elemental composition and textural parameters of the SGF-R and SCS-R samples.

\begin{tabular}{|c|c|c|c|c|c|c|c|}
\hline \multirow{2}{*}{ Sample } & \multicolumn{3}{|c|}{ Elemental Content (wt\%) } & \multirow{2}{*}{$\mathrm{S}_{\mathrm{BET}}{ }^{1}\left(\mathrm{~m}^{2} \mathrm{~g}^{-1}\right)$} & \multirow{2}{*}{$V_{t}^{2}\left(\mathrm{~cm}^{3} \mathrm{~g}^{-1}\right)$} & \multirow{2}{*}{$\mathrm{V}_{\mathrm{mi}}{ }^{3}\left(\mathrm{~cm}^{3} \mathrm{~g}^{-1}\right)$} & \multirow{2}{*}{$V_{m e}{ }^{4}\left(\mathrm{~cm}^{3} \mathrm{~g}^{-1}\right)$} \\
\hline & $\mathrm{C}$ & $\mathbf{H}$ & $\mathbf{N}$ & & & & \\
\hline GR & 87.32 & 0.90 & 0.72 & 750 & 1.00 & 0.13 & 0.87 \\
\hline SGF-3:1 & 90.18 & 0.71 & 0.60 & 1111 & 0.70 & 0.11 & 0.59 \\
\hline SCS-3:1 & 67.79 & 1.54 & 1.97 & 1313 & 0.60 & 0.13 & 0.47 \\
\hline SGF-5:3 & 79.72 & 1.13 & 0.30 & 771 & 0.52 & 0.20 & 0.32 \\
\hline SCS-5:3 & 62.49 & 1.97 & 2.13 & 841 & 0.37 & 0.30 & 0.07 \\
\hline
\end{tabular}

${ }^{1} \mathrm{~S}_{\mathrm{BET}}$ - total specific surface area, ${ }^{2} \mathrm{~V}_{\mathrm{t}}$-volume of total pores; ${ }^{3} \mathrm{~V}_{\mathrm{mi}}$-volume of micropores; ${ }^{4} \mathrm{~V}_{\mathrm{me}}$-volume of mesopores. 
The nitrogen adsorption-desorption isotherms of the carbon prepared from sucrose possess the appropriate distinct shape of carbon obtained with graphene or chitosan (Figure 2a,b). The shapes of isotherms belong to type I and IV, according to the International Union of Pure and Applied Chemistry (IUPAC) classification [36]. Using sucrose and graphene or chitosan primarily creates micropores in the structure. As listed in Table 1, the $\mathrm{N}_{2}$ adsorption experiments indicate that the highest BET surface area is $1111 \mathrm{~m}^{2} \mathrm{~g}^{-1}$ for SGF-3:1 and $1313 \mathrm{~m}^{2} \mathrm{~g}^{-1}$ for SCS-3:1. Interestingly, the surface areas of samples obtained at a 5:3 weight ratio (lower sucrose content) are lower than those of samples at the 3:1 ratio. The specific surface areas for samples SGF-5:3 and SCS-5:3 are 771 and $841 \mathrm{~m}^{2} \mathrm{~g}^{-1}$, respectively. The total pore volume is given in the range of 0.37 to $0.70 \mathrm{~cm}^{3} \mathrm{~g}^{-1}$. Figure $2 \mathrm{c}, \mathrm{d}$ provides pore size distribution as obtained using the NLDFT; size distribution appears to be quite narrow. The two different mass ratios of graphene to sucrose $(3: 1,5: 3)$ affect pore size. For samples SCS-3:1 and SGF-3:1, micropore size ranges from 0.5 to $1.8 \mathrm{~nm}$. Samples SCS-5:1 and SGF-5:3 show micropores and small mesopores, up to $3.75 \mathrm{~nm}$. The pore size distribution shows that sucrose-derived carbon obtained without any activator would be a suitable electrode material for supercapacitors $[37,38]$.

(a)

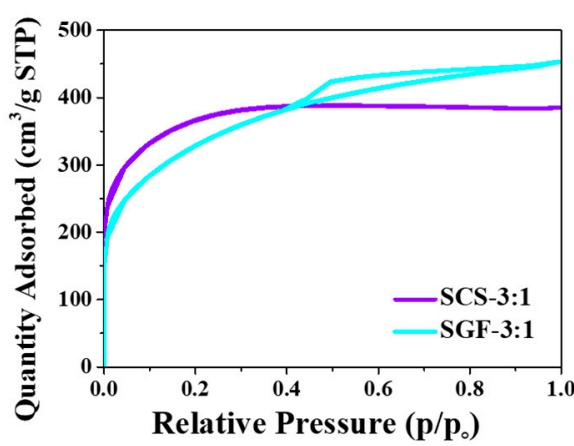

(c)

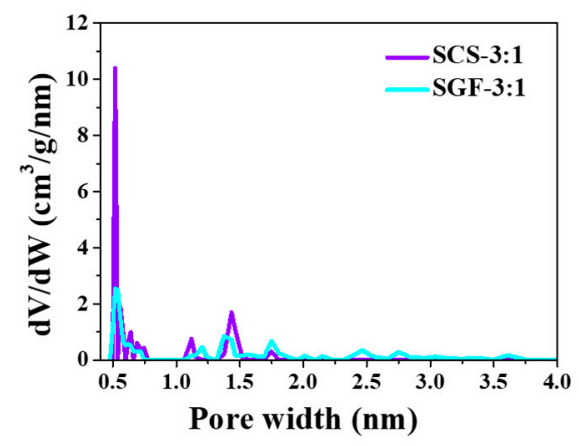

(b)

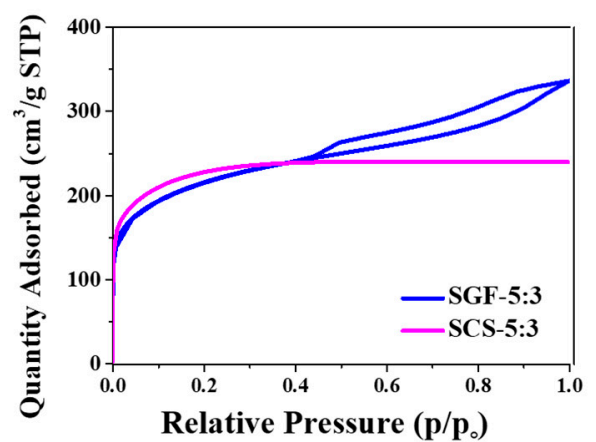

(d)

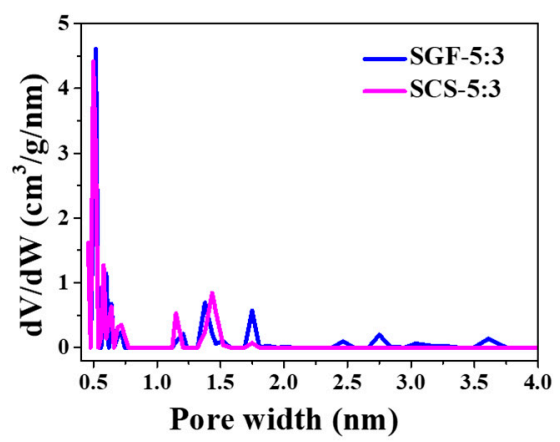

Figure 2. (a,b) $\mathrm{N}_{2}$ adsorption-desorption isotherms at $77 \mathrm{~K} ;(\mathbf{c}, \mathbf{d})$ nonlocalized density functional theory (NLDFT) pore size distribution obtained from adsorption branches of $\mathrm{N}_{2}$ in the SGF-R and SCS-R samples.

Elemental composition results are given in Table 1. Influence of graphene and chitosan on the carbon and nitrogen content is observable. Use of graphene (GR) caused carbon content to increase to 79.72-90.18 wt.\%. For the samples obtained with chitosan, carbon content decreased to 62.49-67.79 wt.\%. Generally, higher carbon content is reported for samples synthesized with a higher amount of sucrose. The content of nitrogen for samples obtained with chitosan is 1.97 wt.\% for SCS-3:1 and 2.13 wt.\% for SCS-5:3, while the nitrogen content for samples obtained with graphene significantly decreased and is only $0.60 \mathrm{wt}$. \% for sample SGF-3:1 and $0.3 \mathrm{wt}$. \% for SGF-5:3. The reason behind the low nitrogen content is a lack of nitrogen precursors.

Raman spectroscopy was used to characterize the graphitization degree of carbon materials [39,40]. Figure 3 shows Raman spectra for the carbon materials synthesized from sucrose and chitosan or graphene. In all cases, Raman spectra exhibit the D-band, G-band, 
and 2D-band at a shift of $\sim 1340 \mathrm{~cm}^{-1}, \sim 1580 \mathrm{~cm}^{-1}$, and $\sim 2700 \mathrm{~cm}^{-1}$, respectively. The intensity ratio of the D- and G-bands determines the level of graphitization $[14,41,42]$. The materials here show a disordered location of graphene with the intensity of the D-band and G-band $\left(\mathrm{I}_{\mathrm{D}} / \mathrm{I}_{\mathrm{G}}\right)$ at 1 (Table 2 ). The lack of significant differences in the $\mathrm{I}_{\mathrm{D}} / \mathrm{I}_{\mathrm{G}}$ ratio confirms that using sucrose causes defects in the carbon structure.

(a)

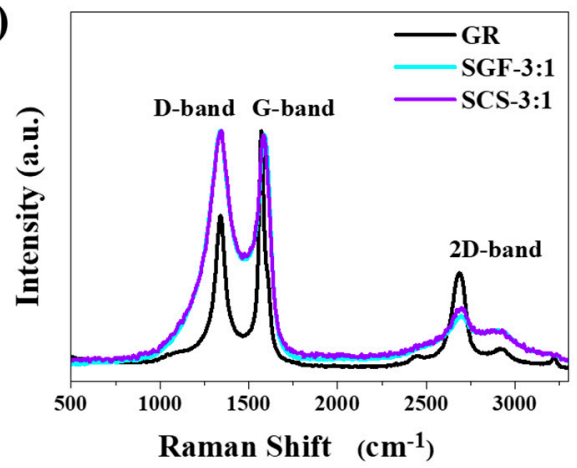

(b)

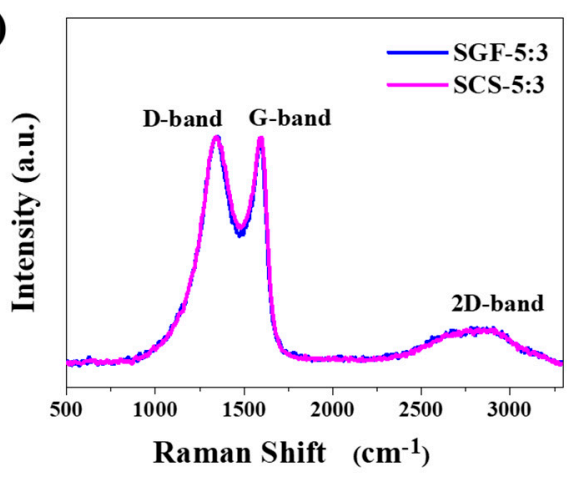

Figure 3. Raman spectra of (a) graphene, SGF-3:1 and SCS-3:1, (b) SGF-5:3 and SCS-5:3 sample.

Table 2. Fitting results of the Raman spectra for graphene (GR), SGF-R, and SCS-R samples.

\begin{tabular}{|c|c|c|c|c|c|c|c|c|}
\hline Sample & $\mathbf{I}_{\mathbf{D}}$ & Raman Shift $\left(\mathrm{cm}^{-1}\right)$ & $\mathbf{I}_{\mathrm{G}}$ & Raman Shift $\left(\mathrm{cm}^{-1}\right)$ & $\mathbf{I}_{2 \mathrm{D}}$ & Raman Shift $\left(\mathrm{cm}^{-1}\right)$ & $\mathbf{I}_{\mathrm{D}} / \mathrm{I}_{\mathrm{G}}$ & $\mathbf{I}_{2 \mathrm{D}} / \mathrm{I}_{\mathrm{G}}$ \\
\hline GR & 0.64 & 1341 & 1 & 1570 & 0.4 & 2686 & 0.64 & 0.4 \\
\hline SGF-3:1 & 1 & 1339 & 0.99 & 1587 & 0.23 & 1699 & 1.02 & 0.23 \\
\hline SCS-3:1 & 1 & 1341 & 0.99 & 1593 & 0.2 & 2779 & 1.01 & 0.2 \\
\hline SGF-5:3 & 1 & 1346 & 0.98 & 1583 & 0.26 & 2699 & 1.02 & 0.26 \\
\hline SCS-5:3 & 1 & 1341 & 1 & 1598 & 0.19 & 2755 & 1 & 0.19 \\
\hline
\end{tabular}

However, materials synthesized from ingredients in a 3:1 ratio have a 2D-band which is more pronounced. As the 2D-band decreases, the number of graphene structure defects increases, which is observable for series 5:3. Thus, a transition from a few-layer graphene structure to an amorphous carbon material can be seen $[43,44]$. A higher number of overlapping graphene layers is observed, and therefore, relative intensities of the 2D-band and $\mathrm{G}$-band $\left(\mathrm{I}_{2 \mathrm{D}} / \mathrm{I}_{\mathrm{G}}\right)$ are low, around 0.2 .

The porous carbon material's surface element composition and chemical states of atoms were analyzed and characterized by XPS. In order to understand the chemical state of carbon, oxygen, and nitrogen atoms, XPS was recorded for samples SGF-3:1 and SCS-3:1; the results are presented in Figure 4.

The C1s spectrum is shown in Figure $4 \mathrm{a}$, where two main characteristic peaks can be fitted: the peak with the strongest intensity at $284.6 \mathrm{eV}$, which corresponds to the presence of $\mathrm{sp}^{2} \mathrm{C}=\mathrm{C}$ bonds, and a characteristic peak at $285.0 \mathrm{eV}$, which corresponds to $\mathrm{sp}^{3} \mathrm{C}-\mathrm{C}$ bonds [45-47]. The C1s spectrum of samples was also deconvoluted and assigned to C-O-C bonds $(286.3 \mathrm{eV}), \mathrm{C}=\mathrm{O}$ or $\mathrm{O}-\mathrm{C}-\mathrm{O}$ bonds $(287.7 \mathrm{eV}), \mathrm{O}-\mathrm{C}=\mathrm{O}$ bond $(288.6 \mathrm{eV})$, and $\pi-\pi$ (289.6 eV and $292.1 \mathrm{eV}$ ) [48]. The spectrum of O1s is shown in Figure 4b, where two main characteristic peaks can be fitted: the most important peak at $532.0 \mathrm{eV}$, corresponding to the $\mathrm{C}-\mathrm{O}-\mathrm{C}$ group [49], and the peak at $533.3 \mathrm{eV}$, corresponding to the $\mathrm{O}-\mathrm{C}=\mathrm{O}$ group [50]. The presence of oxygen and the corresponding functional groups can produce pseudo capacitor-induced currents and improve the wettability of the electrode material's surface. This increases the amount of surface charge storage, thus helping to increase the energy density of the supercapacitor. XPS analysis evidenced the presence of nitrogen groups in the SGF-3:1 and SCS-3:1 sucrose-based foams. The results reveal that different samples present a different number of nitrogen heteroatoms. SGF-3:1 shows $0.9 \%$ at., while SCS-3:1 shows a higher nitrogen content of $2.1 \%$ at. In the case of SGF-3:1, there was no peak observed for nitrogen in the N1s region. Hence, it can be concluded that chitosan is responsible for the $\mathrm{N}$-doping. One type of N-based species was identified in doped SCS-3:1, from the N1s XPS 
high-resolution spectrum (Figure 4c), assigned to quaternary-N (N-Q) at $400.7 \mathrm{eV}$ [50-53]. It is important to point out that when $\mathrm{N}$ is incorporated into SCS-3:1, the relative contribution of N-species other than quaternary-N is increased compared to SGF-3:1. The N1s spectra imply that $\mathrm{N}$ atoms have partially substituted $\mathrm{C}$ atoms in the carbon lattice. The XPS spectrum of P2p (Figure $4 \mathrm{~d}$ ) in both samples presents two characteristic bonds of $\mathrm{P}-\mathrm{C}$ and $\mathrm{P}-\mathrm{O}$ at binding energies of $133.5 \mathrm{eV}$ and $134.3 \mathrm{eV}$ [54].

(a)

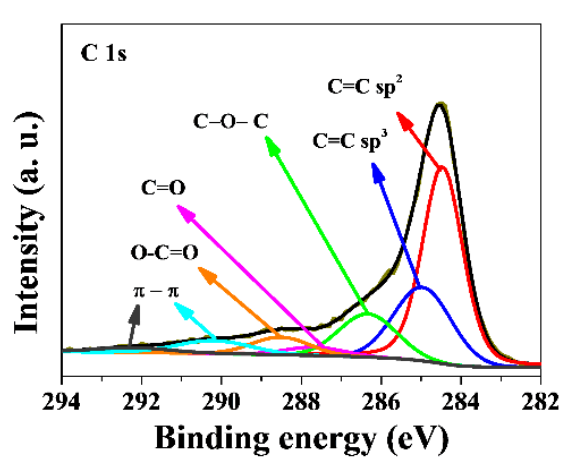

(c)

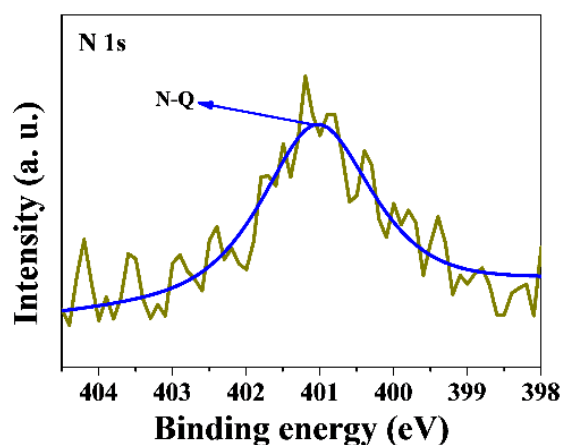

(b)

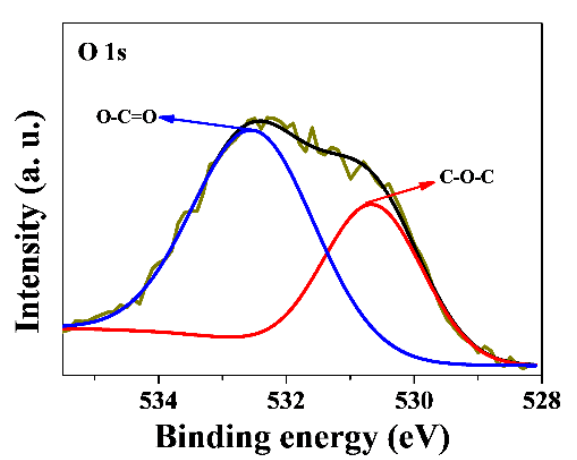

(d)

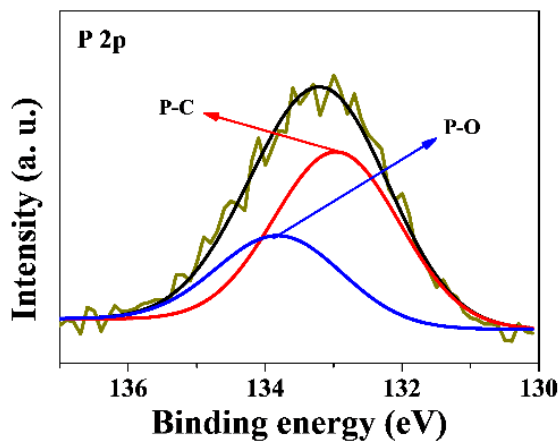

Figure 4. High-resolution XPS spectra: (a) C1s; (b) O1s, (c) N1s, and (d) P2p for the SCS-3:1 sample.

\subsection{Electrochemical Performance}

Experimental results show that the carbon obtained from sucrose with no activator, only graphene and chitosan, possesses properties important for energy storage. The rectangular shape of the $\mathrm{CV}$ curve portrays fast re-organization of the electrical double layer at switching potentials and indicates fast ion transport, provided by an ideal EDLC charge storage mechanism [55-57]. A rectangular shape was observed in the curves of both the SCS-3:1 and the SGF-3:1 electrode, implying ideal double-layer capacitance behavior (Figure 5a,b). For sample SCS-3:1, the CV shape in a two-electrode cell is rectangular in all scan rates. The pore size distribution for series 3:1 is strictly microporous without any mesopores, and therefore, BET is higher for this series; these electrodes should possess the highest capacitance and the lowest resistance [58,59]. A key role in determining specific capacitance is played by the specific surface area and microporosity with a pore size larger than the ions of those electrolytes [60]. 
(a)

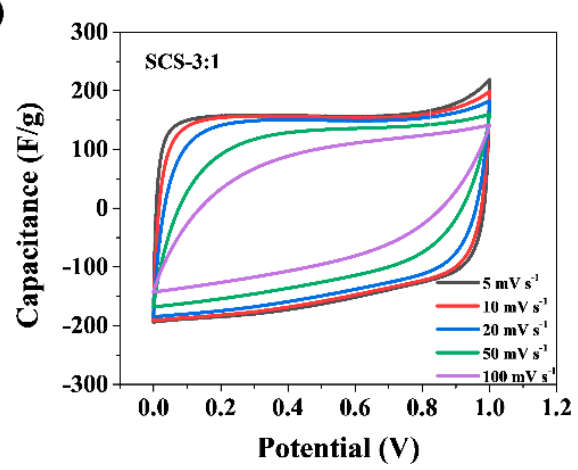

(c)

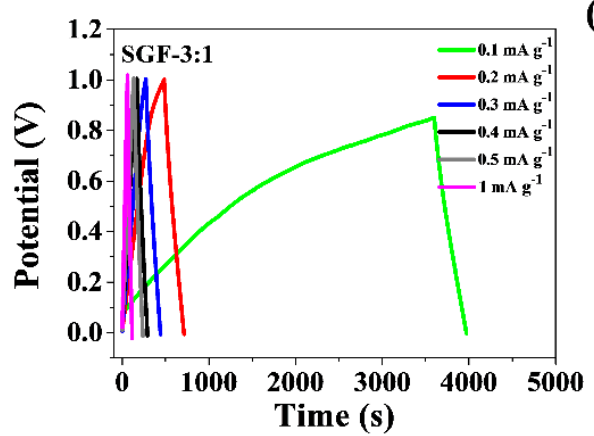

(b)

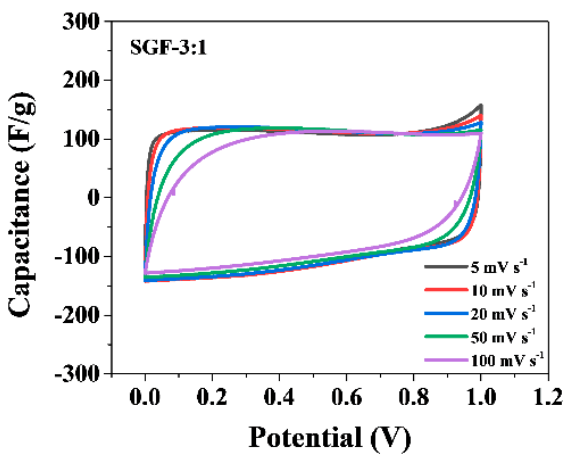

(d)

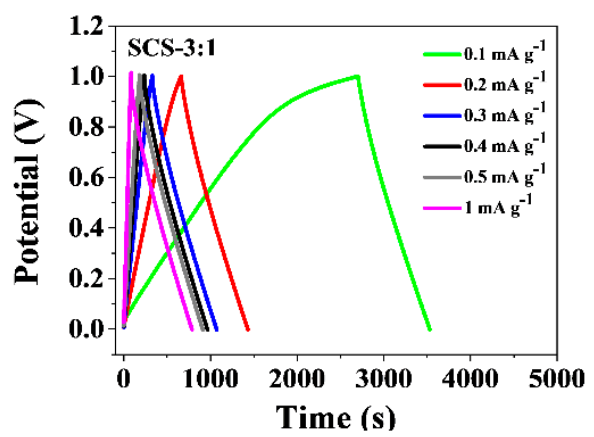

Figure 5. Electrochemical performance tests of the SCS-3:1 and SGF-3:1 samples: (a,b) cyclic voltammetry (CV) profiles at different scan rates ranging from 5 to $100 \mathrm{mV} \mathrm{s}^{-1}$; (c,d) galvanostatic chargedischarge curves.

Specific capacitance $\left(C_{S}\right)$ was calculated using galvanostatic discharge curves (Figure $5 c, d$ ). Looking at the charge-discharge curves of the SCS-3:1 and SGF-3:1 samples, electrode SCS-3:1 shows the highest capacitance. When the current density equaled $1 \mathrm{~A} \mathrm{~g}^{-1}$, the specific capacitance was $143 \mathrm{~F} \mathrm{~g}^{-1}$ for electrode SCS-3:1, and when it equaled $2 \mathrm{~A} \mathrm{~g}^{-1}$, the specific capacitance was $107 \mathrm{~F} \mathrm{~g}^{-1}$ for SGF-3:1 (Figure 6a,b). When compared with other materials [61], those tested show a similar range of supercapacitor operation, in the range of 0 to $0.8 \mathrm{~V}$. Naturally sourced materials' specific capacity also trends similarly to the others, being within the range of $39-246 \mathrm{~F}^{-1}$. The difference between performance and capacity is caused by the presence of different functional groups on the surface, conductivity, wettability in electrolyte, and pore size, from which the diffusion barrier arises [50-52]. The N-Q functional groups identified in sample SCS-3:1 would benefit the enhancement of electrical conductivity, as well as capacitance, by interacting with anions in the alkaline electrolyte $[50,62,63]$. These microporous materials offer sufficient space to allow electrolyte ion transportation and thus improve performance in supercapacitors.

The specific capacity of the SGF-3:1 electrode increases from the initial value to $104 \mathrm{~F} \mathrm{~g}^{-1}$ due to self-activation, then after 200 discharge cycles, there is a slow decrease in the specific capacity value (97\% (102\%) retention after 1000 cycles). The SCS-3:1 electrode exhibits a similar disposition. The specific capacity is slowly increased to $132 \mathrm{~F} \mathrm{~g}^{-1}$ for 100 cycles, followed by a decrease in the specific capacity value, also at $97 \%(101 \%)$ retention after 1000 cycles (Figure 6b). These results indicate that microporous, sucrose-based carbon electrodes used in supercapacitors have good stability and capacitance retention. The plot presented in Figure 6c shows the relationship between energy densities and power densities, calculated from the charge-discharge measurements. Materials obtained with the proposed method show an energy density of $4.7 \mathrm{Wh} \mathrm{kg}^{-1}$ at a power density of $2.8 \mathrm{~kW} \mathrm{~kg}^{-1}$ for SGF-3:1 and an energy density of $6.2 \mathrm{Wh} \mathrm{kg}^{-1}$ at a power density of $2.8 \mathrm{~kW} \mathrm{~kg}^{-1}$ for SCS-3:1. At the same time, cellulose materials show an energy density of $13 \mathrm{Wh} \mathrm{kg}^{-1}$ at a power density of $27 \mathrm{~kW} \mathrm{~kg}^{-1}$. In another example of activated carbon nanotubes exhibiting 
an energy density of $1.0 \mathrm{Wh} \mathrm{kg}^{-1}$ at a power density of $14.4 \mathrm{~kW} \mathrm{~kg}^{-1}$ [64], the obtained foams show similar electrochemical properties.

(a)

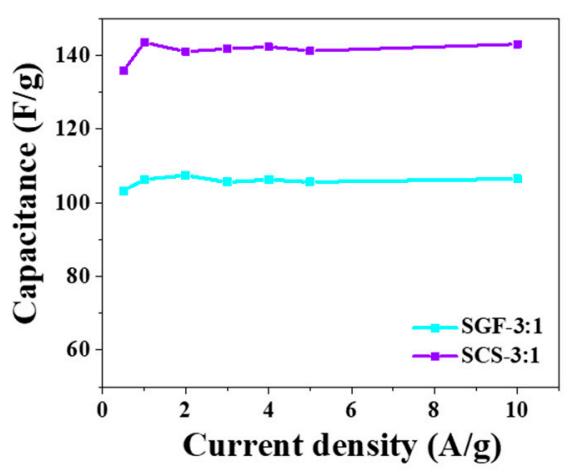

(c)

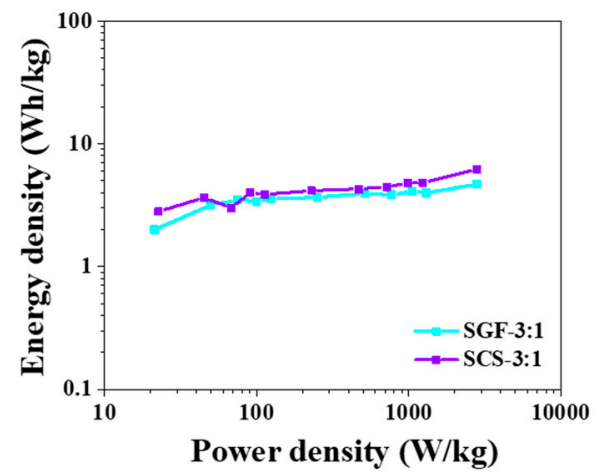

(b)

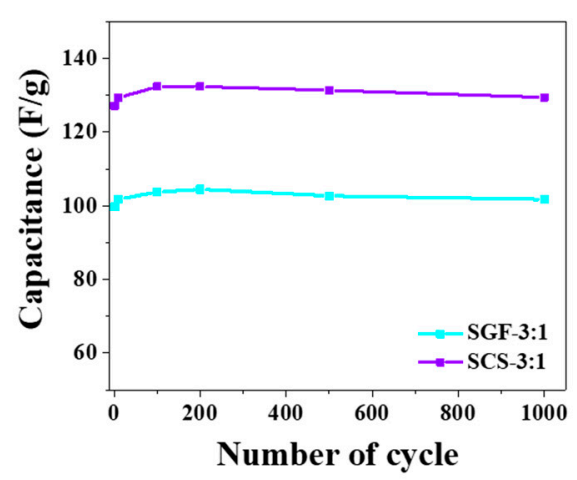

(d)

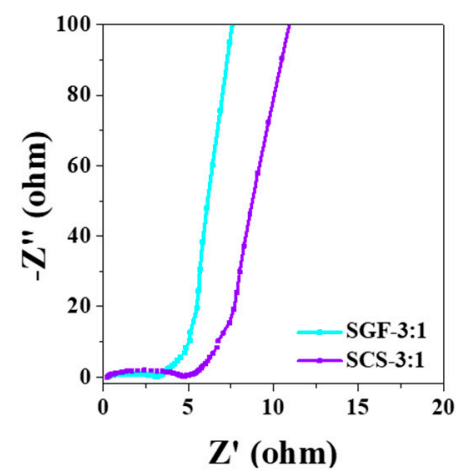

Figure 6. Electrochemical performance tests of the SCS-3:1 and SGF-3:1 samples: (a) specific capacitance as a function of current density; (b) specific capacitance as a function of cycle number; (c) specific capacitance as a function of power density; (d) Nyquist plot.

Figure $6 \mathrm{~d}$ shows the electrochemical impedance spectra of electrodes SCS-3:1 and SGF-3:1, in a frequency range of $10^{-1}$ to $10^{5} \mathrm{~Hz}$. Nyquist plots of the samples showed typical features of porous electrodes with an irregular semicircle at high frequencies, a relatively short $45^{\circ}$ Warburg region at high-medium frequencies, and a slash at low frequencies. At low frequencies, the SMC-800 electrode exhibits an almost vertical line, owing to the high specific surface area and pore size distribution of SCS-3:1, coupled with the electrolyte easily penetrating into its pores [65]. These results indicate that the SCS-3:1 electrode has an almost ideal capacitance at low frequencies and good frequency response performance in accordance with the capacity calculated from the galvanostatic charge-discharge curves $[6,66]$.

\section{Conclusions}

The obtained results fully meet the expectations arising from the previously presented research motivation. The present synthesis procedure has the advantage of being a singlestep approach and only involving the use of simple organic precursors (sucrose and chitosan as carbon and nitrogen sources), plus graphene and $\mathrm{H}_{3} \mathrm{PO}_{4}$ during carbonization. The samples exhibit a correlation between the amount of sucrose used and their textural properties, especially surface area and pore volume. When the ratio of graphene to sucrose is 3:1, the BET is higher. The SGF-R and SCS-R samples show a microporous structure with small mesopores below $4 \mathrm{~nm}$. The sucrose-based carbon SCS-3:1 is a combination of sucrose and chitosan (carbon and nitrogen source) with the highest specific surface area of $1313 \mathrm{~m}^{2} \mathrm{~g}^{-1}$. Cyclic voltammetry (CV), electrochemical impedance spectroscopy (EIS), and galvanostatic charge-discharge cycle tests have been applied to investigate the capacitive performance of the SGF-R and SCS-R electrodes, in $6 \mathrm{M} \mathrm{KOH}$, at room 
temperature. Electrochemical test results demonstrate that when the ratio of graphene and sucrose is equal to 3:1, the composite cathode for supercapacitors has a more stable performance than other samples. The SGF-R and SCS-R electrodes in $6 \mathrm{M} \mathrm{KOH}$ show specific capacitance in excess of $143 \mathrm{~F} \mathrm{~g}^{-1}$ at room temperature.

Author Contributions: Conceptualization, J.P.L.; methodology, J.P.L., P.K., A.I., and M.S.; formal analysis, M.S., A.I., and P.K.; investigation, M.S., P.K., and A.I.; data curation, M.S. and A.I.; writingoriginal draft preparation, A.I., M.S., and P.K.; writing-review and editing, A.I., M.S., and J.P.L.; visualization, M.S. and A.I.; supervision, J.P.L. and A.I.; project administration, M.S.; funding acquisition, M.S. All authors have read and agreed to the published version of the manuscript.

Funding: This research was funded by the National Science Centre, grant number 2019/35/N/ST5/02691.

Institutional Review Board Statement: Not applicable.

Informed Consent Statement: Not applicable.

Data Availability Statement: The data presented in this study are available on request from the corresponding author.

Acknowledgments: The authors would like to thank Daniell Cariazzo and Gelines Moreno-Fernández for valuable advice as well as the opportunity to implement a research internship at the CIC energiGUNE research institute, the PROM project-International scholarship exchange of doctoral students and academic staff as well as the "Excellence Initiative-Mobility for PhD students" under the program "Excellence Initiative-Research Learning".

Conflicts of Interest: The authors declare no conflict of interest.

\section{References}

1. Cano-Casanova, L.; Amorós-Pérez, A.; Ouzzine, M.; Román-Martínez, M.C.; Lillo-Rodenas, M.A. Enhancement of the TiO 2 photoactivity for propene oxidation by carbon incorporation using saccharose in hydrothermal synthesis. J. Environ. Chem. Eng. 2020, 9, 104941. [CrossRef]

2. Matos, J.; Laine, J. A carbon macro-network from the controlled pyrolysis of saccharose. J. Mater. Sci. Lett. 1998, 17, 649-651. [CrossRef]

3. Kubota, K.; Shimadzu, S.; Yabuuchi, N.; Tominaka, S.; Shiraishi, S.; Abreu-Sepulveda, M.; Manivannan, A.; Gotoh, K.; Fukunishi, M.; Dahbi, M. Structural Analysis of Sucrose-Derived Hard Carbon and Correlation with the Electrochemical Properties for Lithium, Sodium, and Potassium Insertion. Chem. Mater. 2020, 32, 2961-2977. [CrossRef]

4. Bernard, S.; Beyssac, O.; Benzerara, K.; Findling, N.; Tzvetkov, G.; Brown, G.E. XANES, Raman and XRD study of anthracenebased cokes and saccharose-based chars submitted to high-temperature pyrolysis. Carbon 2010, 48, 2506-2516. [CrossRef]

5. Myronyuk, I.F.; Mandzyuk, V.I.; Sachko, V.M.; Gun'ko, V.M. Structural features of carbons produced using glucose, lactose, and saccharose. Nanoscale Res. Lett. 2016, 11, 1-9. [CrossRef] [PubMed]

6. Wei, L.; Yushin, G. Electrical double layer capacitors with sucrose derived carbon electrodes in ionic liquid electrolytes. J. Power Source 2011, 196, 4072-4079. [CrossRef]

7. Bai, J.; Lu, B.; Bo, X.; Guo, L. Electrochemical property and electroanalytical application of large mesoporous carbons. Electrochem. Commun. 2010, 12, 1563-1567. [CrossRef]

8. Gao, Z.; Zhu, H.; Li, Y.; Fan, S.; Luo, H.; Xue, J.; Zhang, J. Preparation and electrochemical properties of sucrose-based porous carbon materials by combustion expansion-chemical activation method. J. Appl. Electrochem. 2020, 50, 549-558. [CrossRef]

9. Vazquez-Samperio, J.; Acevedo-Peña, P.; Guzmán-Vargas, A.; Reguera, E.; Cordoba-Tuta, E. Incorporation of heteroatoms into reticulated vitreous carbon foams derived from sucrose to improve its energy storage performance. Int. J. Energy Res. 2020. [CrossRef]

10. Wei, L.; Yushin, G. Electrical double layer capacitors with activated sucrose-derived carbon electrodes. Carbon 2011, 49, 4830-4838. [CrossRef]

11. Krstić, S.; Kragović, M.; Dodevski, V.; Marinković, A.; Kaluđerović, B.; Žerjav, G.; Pintar, A.; Pagnacco, M.; Stojmenović, M. Influence of temperature and different hydroxides on properties of activated carbon prepared from saccharose. Characterization, thermal degradation kinetic and dyes removal from water solutions. Sci. Sinter. 2018, 50, 255-273. [CrossRef]

12. Vahdati-Khajeh, S.; Zirak, M.; Tejrag, R.Z.; Fathi, A.; Lamei, K.; Eftekhari-Sis, B. Biocompatible magnetic N-rich activated carbon from egg white biomass and sucrose: Preparation, characterization and investigation of dye adsorption capacity from aqueous solution. Surf. Interfaces 2019, 15, 157-165. [CrossRef]

13. Woźnica, N.; Hawełek, Ł.; Duber, S.; Fischer, H.; Honkimäki, V.; Pawlyta, M.; Bulou, A.; Burian, A. The atomic scale structure of saccharose-based carbons. Philos. Mag. 2017, 97, 1675-1697. [CrossRef] 
14. Armandi, M.; Bonelli, B.; Geobaldo, F.; Garrone, E. Nanoporous carbon materials obtained by sucrose carbonization in the presence of KOH. Microporous Mesoporous Mater. 2010, 132, 414-420. [CrossRef]

15. Lang, X.; Wang, X.; Li, Y.; Cai, K.; Li, L.; Zhang, Q. Electrochemical performances of KOH activated carbon coated vanadium oxide with sucrose as carbon source for sulfur immobilizers of lithium-sulfur batteries. Sustain. Energy Technol. Assess. 2021, $43,100947$.

16. Zhao, H.; Lu, X.; Wang, Y.; Sun, B.; Wu, X.; Lu, H. Effects of additives on sucrose-derived activated carbon microspheres synthesized by hydrothermal carbonization. J. Mater. Sci. 2017, 52, 10787-10799. [CrossRef]

17. Wang, Q.; Li, H.; Chen, L.; Huang, X. Monodispersed hard carbon spherules with uniform nanopores. Carbon 2001, 39, $2211-2214$. [CrossRef]

18. Kim, J.-K.; Cheruvally, G.; Ahn, J.-H. Electrochemical properties of $\mathrm{LiFePO}_{4} / \mathrm{C}$ synthesized by mechanical activation using sucrose as carbon source. J. Solid State Electrochem. 2008, 12, 799-805. [CrossRef]

19. Wang, K.; Cai, R.; Yuan, T.; Yu, X.; Ran, R.; Shao, Z. Process investigation, electrochemical characterization and optimization of $\mathrm{LiFePO}_{4} / \mathrm{C}$ composite from mechanical activation using sucrose as carbon source. Electrochim. Acta 2009, 54, 2861-2868. [CrossRef]

20. Scherdel, C.; Reichenauer, G. Microstructure and morphology of porous carbons derived from sucrose. Carbon 2009, 47, $1102-1111$. [CrossRef]

21. Li, L.; Song, H.; Chen, X. Ordered mesoporous carbons from the carbonization of sulfuric-acid-treated silica/triblock copolymer/sucrose composites. Microporous Mesoporous Mater. 2006, 94, 9-14. [CrossRef]

22. Ting, C.-C.; Wu, H.-Y.; Vetrivel, S.; Saikia, D.; Pan, Y.-C.; Fey, G.T.K.; Kao, H.-M. A one-pot route to synthesize highly ordered mesoporous carbons and silicas through organic-inorganic self-assembly of triblock copolymer, sucrose and silica. Microporous Mesoporous Mater. 2010, 128, 1-11. [CrossRef]

23. Hwang, J.Y.; Li, M.; El-Kady, M.F.; Kaner, R.B. Next-Generation Activated Carbon Supercapacitors: A Simple Step in Electrode Processing Leads to Remarkable Gains in Energy Density. Adv. Funct. Mater. 2017, 27, 1605745. [CrossRef]

24. Chiu, Y.-H.; Lin, L.-Y. Effect of activating agents for producing activated carbon using a facile one-step synthesis with waste coffee grounds for symmetric supercapacitors. J. Taiwan Inst. Chem. Eng. 2019, 101, 177-185. [CrossRef]

25. Yang, C.; Lan, J.-L.; Liu, W.-X.; Liu, Y.; Yu, Y.-H.; Yang, X.-P. High-performance Li-ion capacitor based on an activated carbon cathode and well-dispersed ultrafine $\mathrm{TiO}_{2}$ nanoparticles embedded in mesoporous carbon nanofibers anode. ACS Appl. Mater. interfaces 2017, 9, 18710-18719. [CrossRef]

26. Feng, J.; Chernova, N.A.; Omenya, F.; Tong, L.; Rastogi, A.C.; Whittingham, M.S. Effect of electrode charge balance on the energy storage performance of hybrid supercapacitor cells based on $\mathrm{LiFePO}_{4}$ as $\mathrm{Li}$-ion battery electrode and activated carbon. J. Solid State Electrochem. 2018, 22, 1063-1078. [CrossRef]

27. Okuda, R.; Nakano, K.; Suematsu, K.; Watanabe, K.; Ilnicka, A.; Łukaszewicz, J.P.; Shimanoe, K. Chemical Activation of Nitrogendoped Carbon Derived from Chitosan with $\mathrm{ZnCl}_{2}$ to Produce a High-performance Gas Diffusion-type Oxygen Electrode. Electrochemistry 2020, 89, 36-42. [CrossRef]

28. Ilnicka, A.; Kamedulski, P.; Skorupska, M.; Lukaszewicz, J.P. Metal-free nitrogen-rich carbon foam derived from amino acids for the oxygen reduction reaction. J. Mater. Sci. 2019, 54, 14859-14871. [CrossRef]

29. Ilnicka, A.; Lukaszewicz, J.P.; Shimanoe, K.; Yuasa, M. Urea treatment of nitrogen-doped carbon leads to enhanced performance for the oxygen reduction reaction. J. Mater. Res. 2018, 33, 1612. [CrossRef]

30. Huang, X.; Xie, Z.; He, X.; Sun, H.; Tong, C.; Xie, D. Electric double layer capacitors using activated carbon prepared from pyrolytic treatment of sugar as their electrodes. Synth. Met. 2003, 135, 235-236. [CrossRef]

31. Guo, P.; Gu, Y.; Lei, Z.; Cui, Y.; Zhao, X. Preparation of sucrose-based microporous carbons and their application as electrode materials for supercapacitors. Microporous Mesoporous Mater. 2012, 156, 176-180. [CrossRef]

32. Subramanian, N.; Viswanathan, B. Nitrogen-and oxygen-containing activated carbons from sucrose for electrochemical supercapacitor applications. RSC Adv. 2015, 5, 63000-63011. [CrossRef]

33. Kumar, R.; Soam, A.; Dusane, R.O.; Bhargava, P. Sucrose derived carbon coated silicon nanowires for supercapacitor application. J. Mater. Sci. Mater. Electron. 2018, 29, 1947-1954. [CrossRef]

34. Simon, P.; Gogotsi, Y. Materials for electrochemical capacitors. Nanosci. Technol. Collect. Rev. Nat. J. 2010, 320-329. [CrossRef]

35. Luo, H.; Yang, Y.; Mu, B.; Chen, Y.; Zhang, J.; Zhao, X. Facile synthesis of microporous carbon for supercapacitors with a $\mathrm{LiNO}_{3}$ electrolyte. Carbon 2016, 100, 214-222. [CrossRef]

36. Thommes, M.; Kaneko, K.; Neimark, A.V.; Olivier, J.P.; Rodriguez-Reinoso, F.; Rouquerol, J.; Sing, K.S. Physisorption of gases, with special reference to the evaluation of surface area and pore size distribution (IUPAC Technical Report). Pure Appl. Chem. 2015, 87, 1051-1069. [CrossRef]

37. Chmiola, J.; Yushin, G.; Gogotsi, Y.; Portet, C.; Simon, P.; Taberna, P.-L. Anomalous increase in carbon capacitance at pore sizes less than 1 nanometer. Science 2006, 313, 1760-1763. [CrossRef]

38. Huber, G.W.; Chheda, J.N.; Barrett, C.J.; Dumesic, J.A. Production of liquid alkanes by aqueous-phase processing of biomassderived carbohydrates. Science 2005, 308, 1446-1450. [CrossRef]

39. Lee, Y.S.; Kim, Y.H.; Hong, J.S.; Suh, J.K.; Cho, G.J. The adsorption properties of surface modified activated carbon fibers for hydrogen storages. Catal. Today 2007, 120, 420-425. [CrossRef] 
40. Paredes, J.; Martinez-Alonso, A.; Yamazaki, T.; Matsuoka, K.; Tascon, J.; Kyotani, T. Structural investigation of zeolite-templated, ordered microporous carbon by scanning tunneling microscopy and Raman spectroscopy. Langmuir 2005, 21, 8817-8823. [CrossRef]

41. Si, W.; Zhou, J.; Zhang, S.; Li, S.; Xing, W.; Zhuo, S. Tunable N-doped or dual N, S-doped activated hydrothermal carbons derived from human hair and glucose for supercapacitor applications. Electrochim. Acta 2013, 107, 397-405. [CrossRef]

42. Hao, P.; Zhao, Z.; Tian, J.; Li, H.; Sang, Y.; Yu, G.; Cai, H.; Liu, H.; Wong, C.; Umar, A. Hierarchical porous carbon aerogel derived from bagasse for high performance supercapacitor electrode. Nanoscale 2014, 6, 12120-12129. [CrossRef] [PubMed]

43. Ferrari, A.; Robertson, J. Resonant Raman spectroscopy of disordered, amorphous, and diamondlike carbon. Phys. Rev. B 2001, 64, 075414. [CrossRef]

44. Ferrari, A.C.; Robertson, J. Interpretation of Raman spectra of disordered and amorphous carbon. Phys. Rev. B 2000, 61, 14095. [CrossRef]

45. Kulkarni, S.B.; Patil, U.M.; Shackery, I.; Sohn, J.S.; Lee, S.; Park, B.; Jun, S. High-performance supercapacitor electrode based on a polyaniline nanofibers/3D graphene framework as an efficient charge transporter. J. Mater. Chem. A 2014, 2, 4989-4998. [CrossRef]

46. Tan, Y.; Xu, C.; Chen, G.; Fang, X.; Zheng, N.; Xie, Q. Facile synthesis of manganese-oxide-containing mesoporous nitrogen-doped carbon for efficient oxygen reduction. Adv. Funct. Mater. 2012, 22, 4584-4591. [CrossRef]

47. Liu, X.; Zhou, Y.; Zhou, W.; Li, L.; Huang, S.; Chen, S. Biomass-derived nitrogen self-doped porous carbon as effective metal-free catalysts for oxygen reduction reaction. Nanoscale 2015, 7, 6136-6142. [CrossRef] [PubMed]

48. Vázquez-Samperio, J.; Sánchez-Padilla, N.; Acevedo-Peña, P.; Cano, A.; Nava, N.; Morales-Acosta, D.; Oliver-Tolentino, M Ni Prussian blue analogue/mesoporous carbon composite as electrode material for aqueous K-ion energy storage: Effect of carbon-framework interaction on its electrochemical behavior. ChemistrySelect 2018, 3, 11441-11450. [CrossRef]

49. Fan, X.; Zhang, L.; Zhang, G.; Shu, Z.; Shi, J. Chitosan derived nitrogen-doped microporous carbons for high performance $\mathrm{CO}_{2}$ capture. Carbon 2013, 61, 423-430. [CrossRef]

50. Hulicova-Jurcakova, D.; Seredych, M.; Lu, G.Q.; Bandosz, T.J. Combined effect of nitrogen-and oxygen-containing functional groups of microporous activated carbon on its electrochemical performance in supercapacitors. Adv. Funct. Mater. 2009, 19, 438-447. [CrossRef]

51. Liu, H.; Song, H.; Chen, X.; Zhang, S.; Zhou, J.; Ma, Z. Effects of nitrogen-and oxygen-containing functional groups of activated carbon nanotubes on the electrochemical performance in supercapacitors. J. Power Source 2015, 285, 303-309. [CrossRef]

52. Seredych, M.; Hulicova-Jurcakova, D.; Lu, G.Q.; Bandosz, T.J. Surface functional groups of carbons and the effects of their chemical character, density and accessibility to ions on electrochemical performance. Carbon 2008, 46, 1475-1488. [CrossRef]

53. Chen, P.; Wang, L.-K.; Wang, G.; Gao, M.-R.; Ge, J.; Yuan, W.-J.; Shen, Y.-H.; Xie, A.-J.; Yu, S.-H. Nitrogen-doped nanoporous carbon nanosheets derived from plant biomass: An efficient catalyst for oxygen reduction reaction. Energy Environ. Sci. 2014, 7, 4095-4103. [CrossRef]

54. Wang, C.; Hu, F.; Yang, H.; Zhang, Y.; Lu, H.; Wang, Q. 1.82 wt.\% Pt/N, P co-doped carbon overwhelms 20 wt.\% Pt/C as a high-efficiency electrocatalyst for hydrogen evolution reaction. Nano Res. 2017, 10, 238-246. [CrossRef]

55. Fang, B.; Binder, L. A modified activated carbon aerogel for high-energy storage in electric double layer capacitors. J. Power Source 2006, 163, 616-622. [CrossRef]

56. Wu, D.; Chen, X.; Lu, S.; Liang, Y.; Xu, F.; Fu, R. Study on synergistic effect of ordered mesoporous carbon and carbon aerogel during electrochemical charge-discharge process. Microporous Mesoporous Mater. 2010, 131, 261-264. [CrossRef]

57. Yuan, D.; Chen, J.; Zeng, J.; Tan, S. Preparation of monodisperse carbon nanospheres for electrochemical capacitors. Electrochem. Commun. 2008, 10, 1067-1070. [CrossRef]

58. Hu, C.-C.; Wang, C.-C. Effects of electrolytes and electrochemical pretreatments on the capacitive characteristics of activated carbon fabrics for supercapacitors. J. Power Source 2004, 125, 299-308. [CrossRef]

59. An, K.H.; Jeon, K.K.; Heo, J.K.; Lim, S.C.; Bae, D.J.; Lee, Y.H. High-capacitance supercapacitor using a nanocomposite electrode of single-walled carbon nanotube and polypyrrole. J. Electrochem. Soc. 2002, 149, A1058. [CrossRef]

60. Pal, B.; Yang, S.; Ramesh, S.; Thangadurai, V.; Jose, R. Electrolyte selection for supercapacitive devices: A critical review. Nanoscale Adv. 2019, 1, 3807-3835. [CrossRef]

61. Zhao, Z.; Hao, S.; Hao, P.; Sang, Y.; Manivannan, A.; Wu, N.; Liu, H. Lignosulphonate-cellulose derived porous activated carbon for supercapacitor electrode. J. Mater. Chem. A 2015, 3, 15049-15056. [CrossRef]

62. Deng, Y.; Xie, Y.; Zou, K.; Ji, X. Review on recent advances in nitrogen-doped carbons: Preparations and applications in supercapacitors. J. Mater. Chem. A 2016, 4, 1144-1173. [CrossRef]

63. Chen, X.; Zhang, J.; Zhang, B.; Dong, S.; Guo, X.; Mu, X.; Fei, B. A novel hierarchical porous nitrogen-doped carbon derived from bamboo shoot for high performance supercapacitor. Sci. Rep. 2017, 7, 1-11. [CrossRef] [PubMed]

64. Shi, K.; Ren, M.; Zhitomirsky, I. Activated carbon-coated carbon nanotubes for energy storage in supercapacitors and capacitive water purification. ACS Sustain. Chem. Eng. 2014, 2, 1289-1298. [CrossRef]

65. Song, H.-K.; Hwang, H.-Y.; Lee, K.-H.; Dao, L.H. The effect of pore size distribution on the frequency dispersion of porous electrodes. Electrochim. Acta 2000, 45, 2241-2257. [CrossRef]

66. Macdonald, D.D. Reflections on the history of electrochemical impedance spectroscopy. Electrochim. Acta 2006, 51, 1376-1388. [CrossRef] 